\title{
Numerical Simulation for Design Evaluation of Thoracic Stent Graft to Investigate the Migration Phenomena and Type 1a Endoleak of Thoracic Aneurysm
}

\author{
Hussam Eddin Altnji, Benyebka Bou-Said* and Helene Walter-Le Berre \\ LAMCOS - INSA de Lyon, Batiment Jean D'alembert 8, Rue Des Sciences - 69621, Villeurbanne, France
}

\begin{abstract}
Migration and endoleak phenomena are considered to be the principal reasons for Endovascular Aneurysm Repair failure. Wide differences of opinion exist regarding the nature of these critical complications. They occur when there is non-complete and ineffective contact between the endograft ends and the wall of the blood vessel. A major goal of present work is to investigate, using the Finite Element Method, the effect of nitinol stent design on the overall effectiveness of contact and radial force. The specific-patient aneurysmal thoracic aorta are challenging. The optimized stent results show better contact stability to resist the migration. They also show a good compromise of stent design requirements (flexibility and stiffness). Moreover, the new design can also prevent the risk of folding or the collapse of stent struts by mitigating the energy of eccentric deformation caused by high angulation and oversizing.
\end{abstract}

Keywords: Aortic aneurysm; Migration; Endoleak type1; Finite element; Stent design

\section{Introduction}

The aneurysmal pathology is characterized by the aorta dilatation as a result of weakness in the aorta wall. This leads to changes in wall tension with reduced tensile strength and finally ruptures. As an alternative to conventional open surgery, Endovascular Aneurysm Repair (EVAR) is a less invasive form of treatment. The primary aim of EVAR is to prevent rupture by exclusion of the aneurysm sac using the concept of a stent graft. However, a secondary criterion concerns the mid- and long-term durability of the stent graft, and this goal remain questionable. The main mid- and long-term mechanically related complications of EVAR are migration and type I endoleaks. An endoleak is defined by persistent blood flow that originates from the proximal attachment site wall. Migration is defined by stent graft slip of more than $10 \mathrm{~mm}$ after deployment. It is generally agreed that both of these complication are the result of inadequate contact between the device and the neck of the aorta [1]. Many clinical investigations were performed to investigate the origin of the ineffective contact interaction (device-aorta) which can be related to one or all of the following factors: endograft under sizing [2,3], high drag forces due to sever angulation $[4,5]$, and insufficient length of proximal attachment site [6,7]. These factors have recently been evaluated using the finite element method (FEM) in the framework of classical continuum computational solid mechanics (CSM) [8]. This work demonstrated that stent graft dimensions (proximal and distal landing zones, and oversizing value) are crucial factors to prevent migration and stent collapse in the case of a highly angulated proximal neck. Additionally, the stent should be flexible enough to allow easy placement and conformity after deployment, specifically in thoracic aorta, which curvature can highly contribute to type1-a endoleaks and device migration [9]. Numerous computational studies have investigated the influence of stent design on vessel scaffolding in the carotid artery [10] and stent placement in cerebral aneurysm [11]. Similarly, the nitinol stent design has been shown to have a considerable impact on crimping and fatigue behavior [12]. More recently, clinical studies have been carried out to investigate the effect of stent design on the radial compliance and stiffness property [13-15] have demonstrated a better flexibility performance of a newly designed stent compared to commercialized stent. To the best of the authors' knowledge, no numerical study was carried to investigate the effect of the thoracic stent design on the contact stiffness in the attachment sites and migration behavior. In this paper, we highlight newly developed stent designs in order to prevent the occurrence of migration and stent collapse [8]. We aim also to investigate the effect of the stent design on the critical, conflicting, and required characteristics of the stent: flexibility and stiffness.

\section{Material and Methods}

\section{Patient specific TAA and stent models}

The FEM patient-specific Thoracic Aortic Aneurysm (TAA) stent models and the deployment procedure were the same as for the previous work $[8,16]$. The aorta material was considered as isotropic hyperplastic, and nearly incompressible. The superelastic proprieties of nitinol were attributed to the stent. We used Abaqus/explicit 6.11 as the finite element solver in a quasi-static analysis with negligible kinetic energy. The general contact algorithm was used for the interactions between all model components. The contact stability index $\mathrm{F}_{\mathrm{cs}}^{-}$was used to define the stick/slip behavior between stent and aorta after stent deployment, by using the following equation:

$$
\begin{aligned}
& \bar{F}_{c s}=\bar{\tau}_{e q} / \mu p, \quad 0 \leq \bar{F}_{c s} \leq 1, \\
& \text { where } \bar{\tau}_{e q} \text { is the equivalent shear, } \tau_{c r i t} \text { represents the critical }
\end{aligned}
$$

*Corresponding author: Benyebka Bou-Said, LAMCOS - INSA de Lyon, Batiment Jean D'alembert 8, Rue Des Sciences - 69621, Villeurbanne, France Tel: 33604672008; E-mail: benyebka.bou-said@insa-lyon.fr

Received February 05, 2015; Accepted February 24, 2015; Published February 26, 2015

Citation: Altnji HE, Said BB, Berre HWL (2015) Numerical Simulation for Design Evaluation of Thoracic Stent Graft to Investigate the Migration Phenomena and Type 1a Endoleak of Thoracic Aneurysm. J Vasc Med Surg 3: 187. doi:10.4172/2329. 6925.1000187

Copyright: $\odot 2015$ Altnji HE, et al. This is an open-access article distributed under the terms of the Creative Commons Attribution License, which permits unrestricted use, distribution, and reproduction in any medium, provided the original author and source are credited. 
shear stress, while $\mu$ is the friction coefficient, and $P$ is the contact pressure.

The compromises in stent design are not trivial. The stents should be as flexible as possible in a highly tortuous aorta leading to a better conformity after deployment. However, sufficient radial strength is a crucial factor to obtain an effective contact and resist the compressive radial forces applied by the vessel. These two critical, stent design requirements are often conflicting and cannot work simultaneously. In such an angulated morphology, our attempt is to search for a new flexible design, which can enable a good radial stiffness to resist aorta recoil and a good contact stability to resist to migration. When a stent with a diameter $D$ and length $L$ is compressed by a virtual catheter, applying a radial pressure $P_{c}$, it will undergo an axial elongation $F_{c}$ and a change in strut angle $\beta$ and diameter. According to Jedwab et al., the radial pressure acting on the stent is given by [17]:

$$
P_{c}=\frac{-2 F_{c}}{D L \tan \beta}
$$

The radial (hoop) stent stiffness $\left(\mathrm{N} / \mathrm{mm}^{3}\right)$ measures the elastic response of the stent to an applied force. The radial stiffness is defined by [18]:

$$
K_{p}=\frac{\partial P_{c}}{\partial D}
$$

The previous analytical equations were implemented in Matlab software to calculate these values. These values were then compared to the numerical FEM values. The numerical results had a good agreement with the analytical representation (results not presented here). These equations could inspire the new stent designs. The proposed designs (Figure 1) were modeled performing variable oversizing values at one or both attachment sties of the stent. For all the new stent designs, the central part of the stent was oversized by $15 \%$ and the end parts by $20 \%$ and $25 \%$, respectively. To evaluate the effect of stent length, these three oversizing values were applied for both lengths of the stent; stent 1 (144 $\mathrm{mm}$ ) and stent $2(160 \mathrm{~mm})$ (Figure 1$)$. Thus, a total of eight simulations were performed.

\section{Results}

Based on the previous results obtained by $[8,16]$; stent 1 , which has a length of $144 \mathrm{~mm}$ of with uniform $15-20 \%$ of oversizing value, had undergone migration failure. The results showed that all the new designed stent 1 (NDSI) with 20\%-25\% oversizing: (NDSI: $1-2$ 3-4) oversized at both proximal and distal ends did not undergo migration failure even in the smoothest contact condition, and with severe angulation where the pullout forces can be high. A very slight improvement of migration $(7.2 \mathrm{~mm})$ resulted when oversizing of 20\%-25\% was imposed at both proximal and distal ends of the stent (NDSI-1 and NDSI-2) (Figure 2). The new design was able to improve the migration behavior by $59 \%$ compared to the old stent design with $15 \%$ uniform oversizing, and improved by $45.8 \%$ compared to the $20 \%$ uniformly oversized case.

Comparing with the old design stent 1 , the new design stents (NDSI) demonstrated lower stiffness, with better flexibility and underwent deployment without migration failure. A very slight decrease in stiffness was reported between the new design stents (NDSI-1, NDSI-2, NDSI-3, NDSI-4) as shown in Figure 3. All the deployed new designed stent 1 (NDSI) resulted in a significant increase in pressure contact area. Although the contact stability improvement was not significant, the slight improvements of contact stability in NDSI-1 and NDSI-2 were able to prevent migration failure (Figure 4 and Table 1).

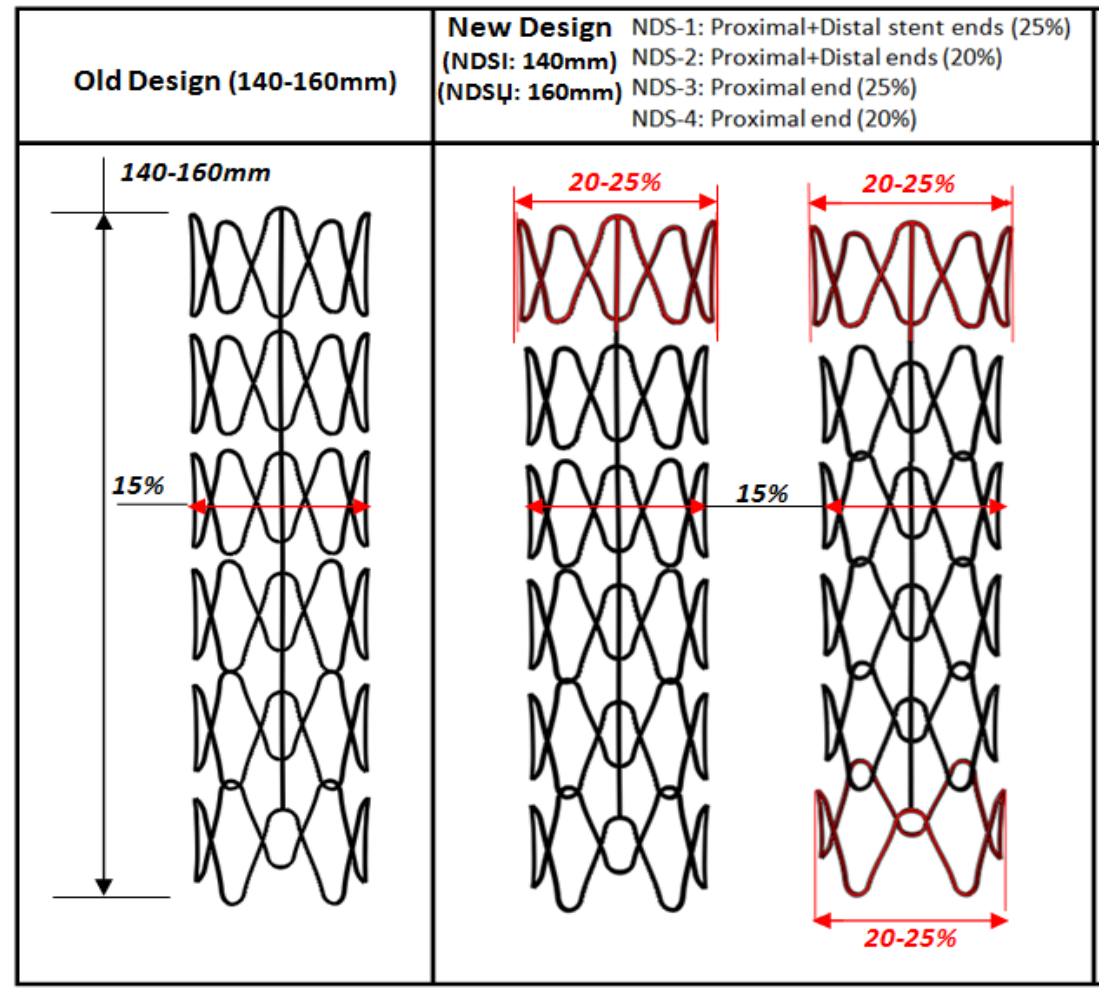

Figure 1: Optimized stent designs for both stent 1 and stent 2. 


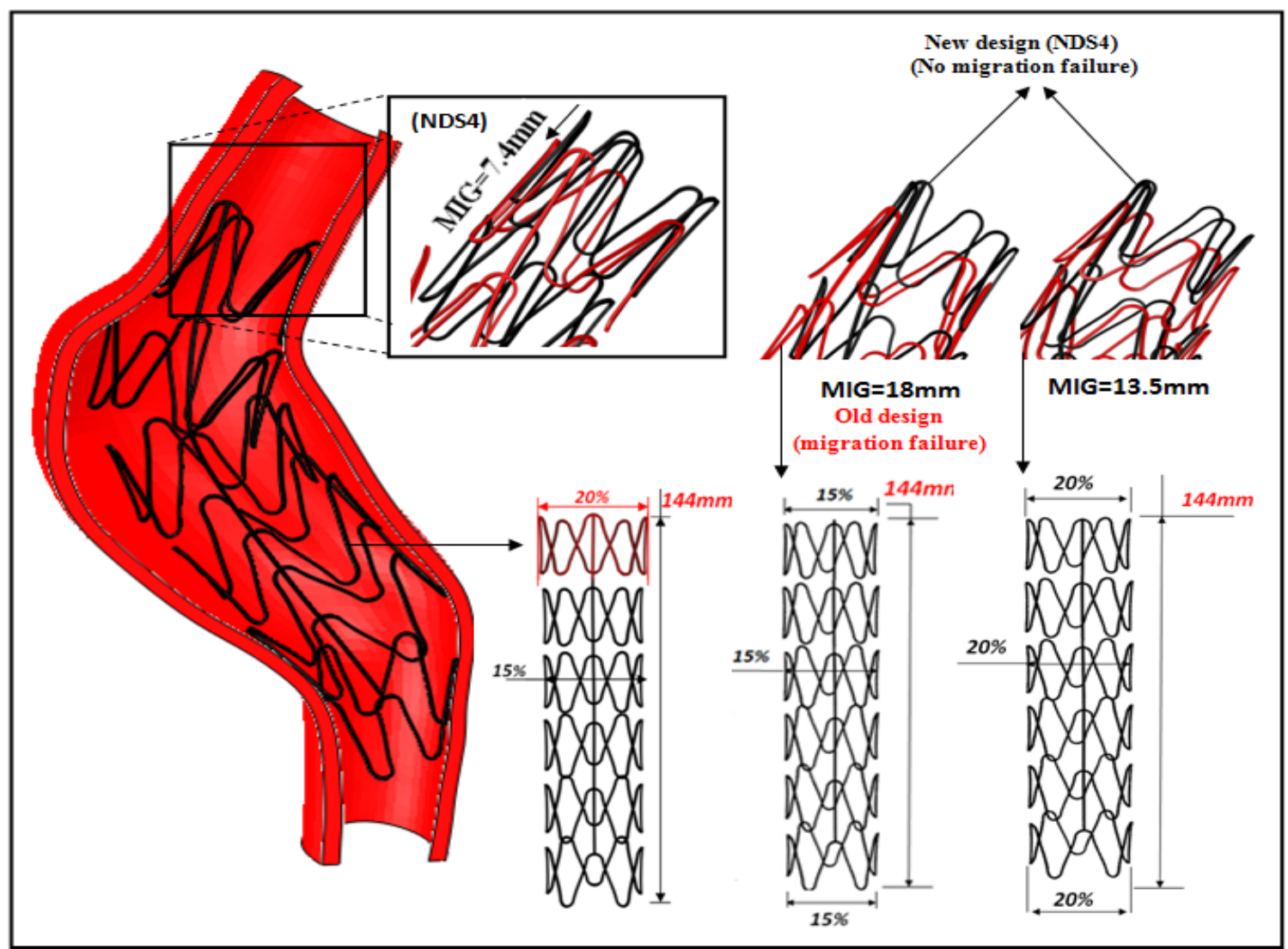

Figure 2: Migration success for the proposed new design for the stent1 (NDSI )-( $\mu=0.05)$.

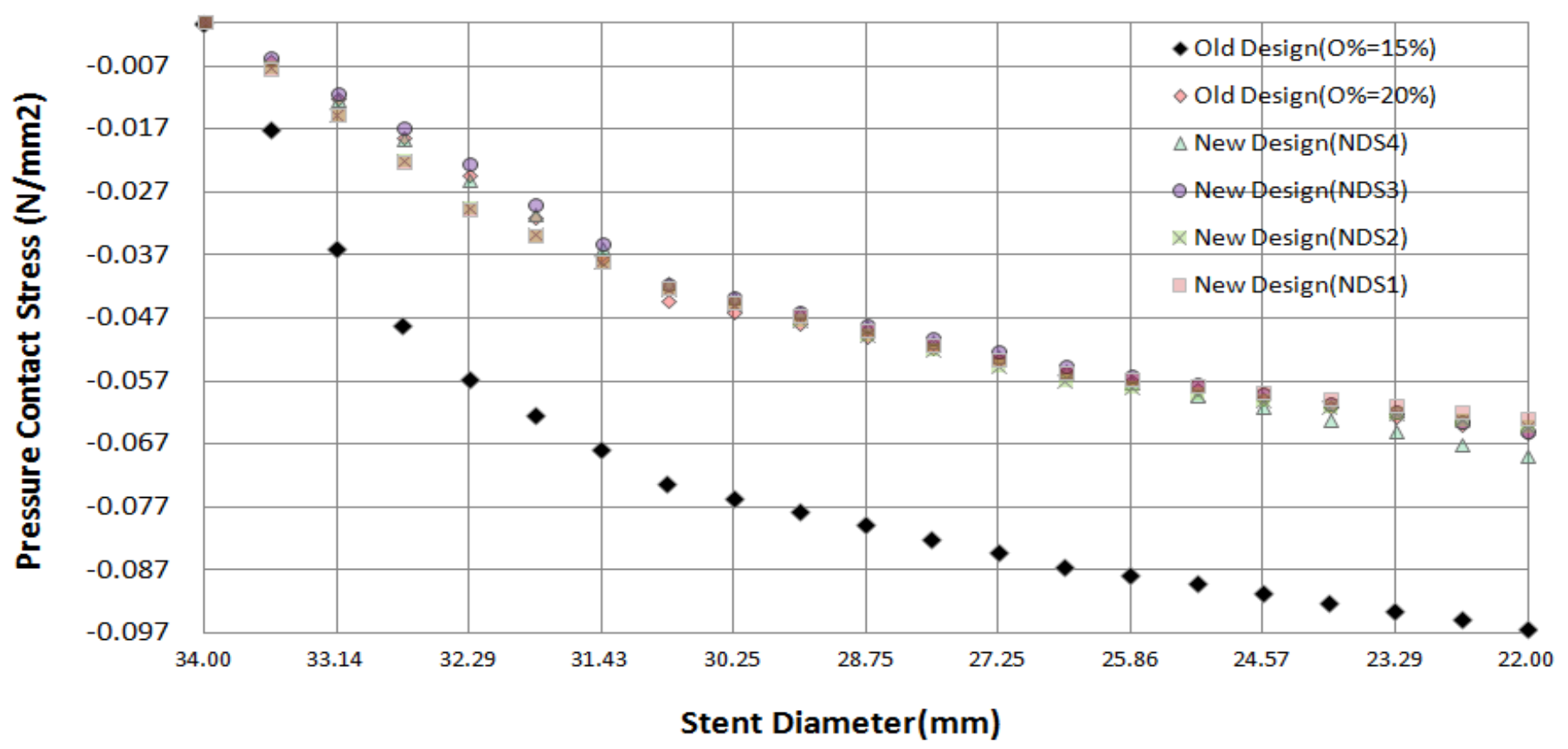

Figure 3: Radial pressure contact as a function of stent diameter for numerical results, new design stent 1 (NDSI), length=144 mm. 
Citation: Altnji HE, Said BB, Berre HWL (2015) Numerical Simulation for Design Evaluation of Thoracic Stent Graft to Investigate the Migration Phenomena and Type 1a Endoleak of Thoracic Aneurysm. J Vasc Med Surg 3: 187. doi:10.4172/2329-6925.1000187

Page 4 of 7

In the case of stent NDSџ, sufficient length of the proximal site $(\mathrm{PASL}=21 \mathrm{~mm})$ resulted in a better contact surface area, and consequently, a better radial strength compared to NDSI. For the newer designed, longer stent 2 (NDSЏ), nearly identical values of stiffness and stresses were obtained compared to the old design stent (with 15\% uniform oversizing), causing better conformity and flexibility between the stent and the vascular anatomy. However, NDSЏ demonstrated a decline of proximal contact stiffness comparing with the old designed stent 2 with 15\% uniform oversizing (Figure 5 and Table 2). Therefore, we suggested extra oversizing (Imp-new design stent 2) for both two circles of the stent which are expected to go into contact against the vessel wall, (Figure 6). The simulation showed neither migration nor collapse. During the crimping process, the Imp-NDSЏ-20\% demonstrated almost the same stiffness of new design NDSЏ-2 and NDSџ-4.

On the other hand, the design Imp-NDSЏ-25\% resulted in an observed decrease of stiffness compared to the Imp-NDSЏ-20\%. Starting from the oversizing $=25 \%$ value, the Imp-NDSЏ stiffness was slightly decreased, Table 3 . The two improved new designs $(20 \%$ and 25\%): Imp-NDSЏ - $20 \%$ and $25 \%$, demonstrated better superelastic recovery during the stent expansion, resulting in a better proximal contact surface diffusion, compared to those where only one circle of the strut at the proximal site was oversized with $20 \%$ or $25 \%$ (Figure 7 and Table 3 ).

\section{Discussion}

All the suggested designs decrease the potential of downward static forces when oversizing the central part with a small value (15\%), i.e., higher values is needed to dislodge the stent1 $(144 \mathrm{~mm})$ from its proximal site. This design resulted in an adequate area of proximal-distal interaction between the stent and the aortic neck, raising the friction and radial force applied by the proximal stent struts. Considering equation (1), decreasing the diameter of the stent is associated with increasing the 'overall radial pressure contact', i.e., higher pressure forces are required for a smaller diameter value. However, critical length with higher oversizing could lead to adverse outcomes. If the stent is not well oversized, adverse outcomes like aorta recoil or stent collapse or migration can result, and smaller values of pullout forces can withdraw the stent leading to deployment failure.

Thus, the results can be explained as follows: with the proposed design, the extra proximal-distal oversized stent ends expanded at the designed oversizing values $20 \%$ or $25 \%$, however, a continued

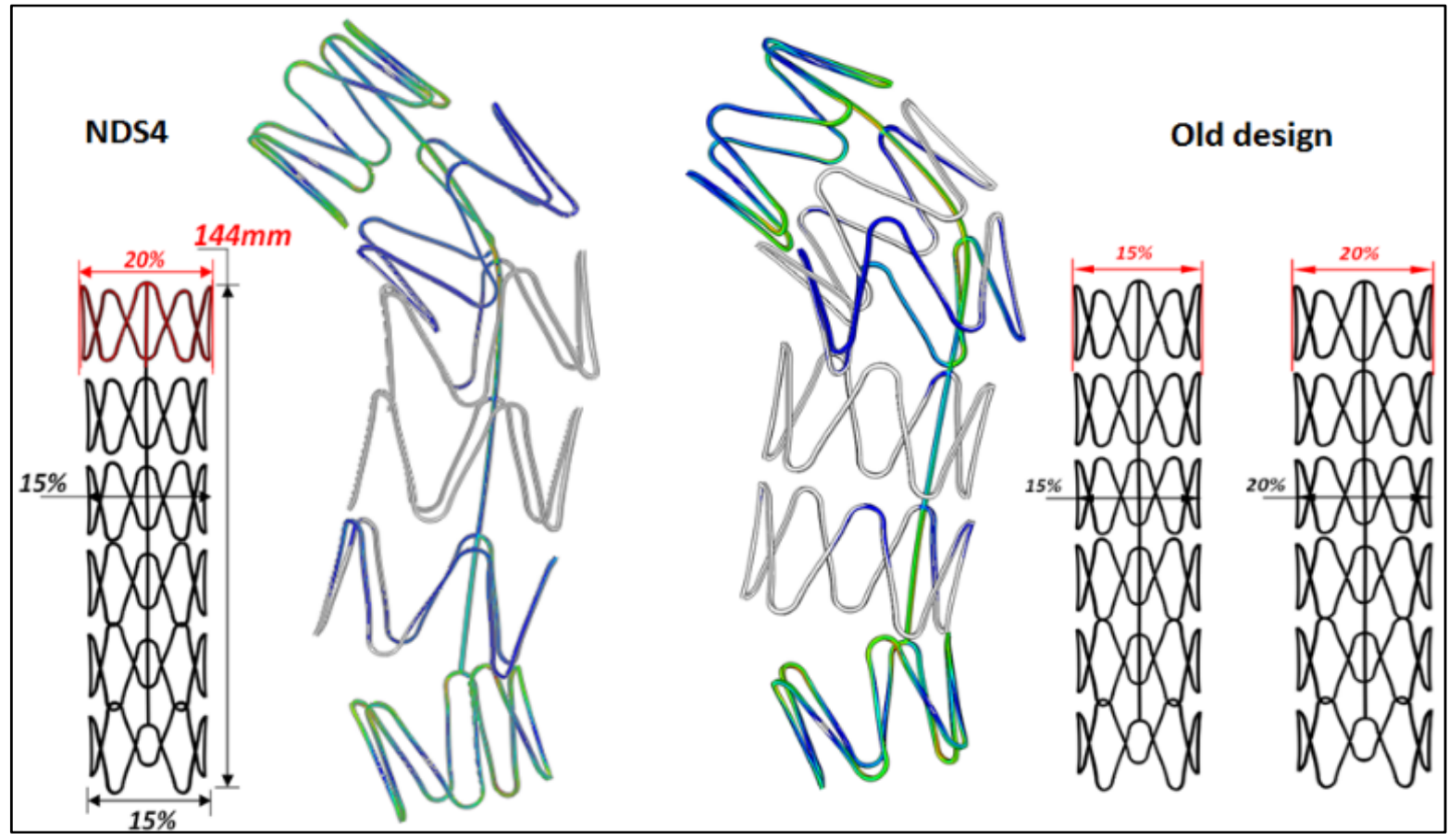

Figure 4: Comparison of superelastic recovery of the struts after deployment between the old (right) and new designed stent 1(NDSI (left).

\begin{tabular}{|c|c|c|c|c|c|}
\hline \multicolumn{6}{|l|}{ Simulation } \\
\hline $\begin{array}{l}\text { Stent models } \\
\text { (PASL) } \\
\text { (DASL) }\end{array}$ & & $\begin{array}{c}\text { Stent2 }(160 \mathrm{~mm}) \\
D_{2 P}=21 \\
D_{2 D}=18 \\
\text { (NDS4) }\end{array}$ & $\begin{array}{c}\text { Stent2 }(160 \mathrm{~mm}) \\
D_{2 P}=21 \\
D_{2 D}=18 \\
\text { (NDS3) }\end{array}$ & $\begin{array}{c}\text { Stent2 }(160 \mathrm{~mm}) \\
D_{2 P}=21 \\
D_{2 \mathrm{P}}=18 \\
\text { (NDS2) }\end{array}$ & $\begin{array}{c}\text { Stent2 }(160 \mathrm{~mm}) \\
D_{2 \mathrm{P}}=21 \\
D_{2 \mathrm{D}}=18 \\
\text { (NDS1) }\end{array}$ \\
\hline \multirow{3}{*}{ Oversizing value (O \%) } & Stent Body & $15 \%$ & $15 \%$ & $15 \%$ & $15 \%$ \\
\hline & Stent Proximal site & $20 \%$ & $25 \%$ & $20 \%$ & $25 \%$ \\
\hline & Stent Distal site & $15 \%$ & $15 \%$ & $20 \%$ & $25 \%$ \\
\hline \multirow[b]{2}{*}{ Contact stability $\left(\bar{F}_{\mathrm{CS}}\right)$} & Proximal neck & 0.92 & 0.91 & 0.92 & 0.94 \\
\hline & Distal neck & 0.98 & 0.97 & 0.88 & 0.90 \\
\hline
\end{tabular}

Table 1: The effect of new design stent 2 ( NDSџ), $L=160 \mathrm{~mm}$; simulation results. 


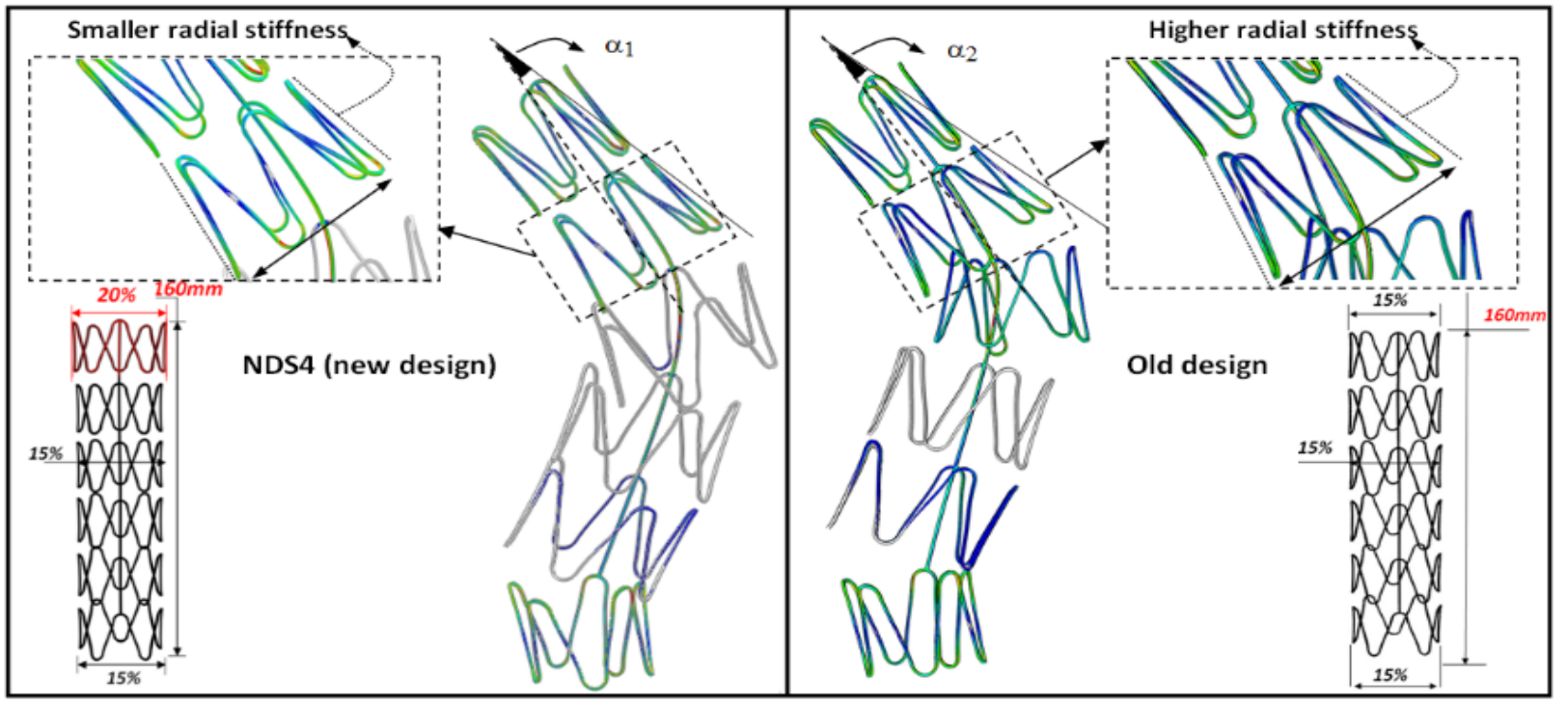

Figure 5: Comparison of superelastic recovery of the struts between the old (right) and new designed stent 2 (NDSџ, left).Best contact stiffness was produced proximally for the old design.

\begin{tabular}{|c|c|c|c|c|c|}
\hline \multicolumn{6}{|l|}{ Tangential contact behavior } \\
\hline $\begin{array}{l}\text { Stent models } \\
\text { (PASL) } \\
\text { (DASL) }\end{array}$ & & $\begin{array}{c}\text { Stent1 } \\
(144 \mathrm{~mm}) \\
D_{1 \mathrm{P}}=18 \\
\mathrm{D}_{1 \mathrm{D}}=15 \\
(\mathrm{NDS} 4)\end{array}$ & $\begin{array}{c}\text { Stent1 } \\
(144 \mathrm{~mm}) \\
D_{1 \mathrm{P}}=18 \\
D_{1 \mathrm{D}}=15 \\
\text { (NDS3) }\end{array}$ & $\begin{array}{c}\text { Stent1 }(144 \mathrm{~mm}) \\
D_{1 \mathrm{P}}=18 \\
D_{1 \mathrm{D}}=15 \\
\text { (NDS2) }\end{array}$ & $\begin{array}{c}\text { Stent1 } \\
(144 \mathrm{~mm}) \\
D_{1 \mathrm{P}}=18 \\
D_{1 \mathrm{D}}=15 \\
\text { (NDS1) }\end{array}$ \\
\hline \multirow[t]{3}{*}{ Oversizing value $(0 \%)$} & Stent Body & $15 \%$ & $15 \%$ & $15 \%$ & $15 \%$ \\
\hline & Stent Proximal site & $20 \%$ & $25 \%$ & $20 \%$ & $25 \%$ \\
\hline & Stent Distal site & $15 \%$ & $15 \%$ & $20 \%$ & $25 \%$ \\
\hline \multirow{2}{*}{ Contact stability $\left(\bar{F}_{\mathrm{CS}}\right)$} & Proximal neck & 0.97 & 0.98 & 0.95 & 0.97 \\
\hline & Distal neck & 0.95 & 0.93 & 0.97 & 0.92 \\
\hline Tangential contact behavior & & $\mu=0.05$ & $\mu=0.05$ & $\mu=0.05$ & $\mu=0.05$ \\
\hline Pressure contact area $\left(\mathrm{mm}^{2}\right)$ after deployment & & 717 & 727 & 734 & 742 \\
\hline \multirow[b]{2}{*}{ Average contact pressure stress $\left(\mathrm{N} / \mathrm{mm}^{2}\right)$} & Proximal neck & $1.76 \mathrm{E}-02$ & 0.0186 & 0.0193 & 0.0180 \\
\hline & Distal neck & 0.015 & 0.016 & 0.0174 & 0.0173 \\
\hline
\end{tabular}

Table 2: The effect of new design stent 1 (NDSI), L = $144 \mathrm{~mm}$; simulation results.

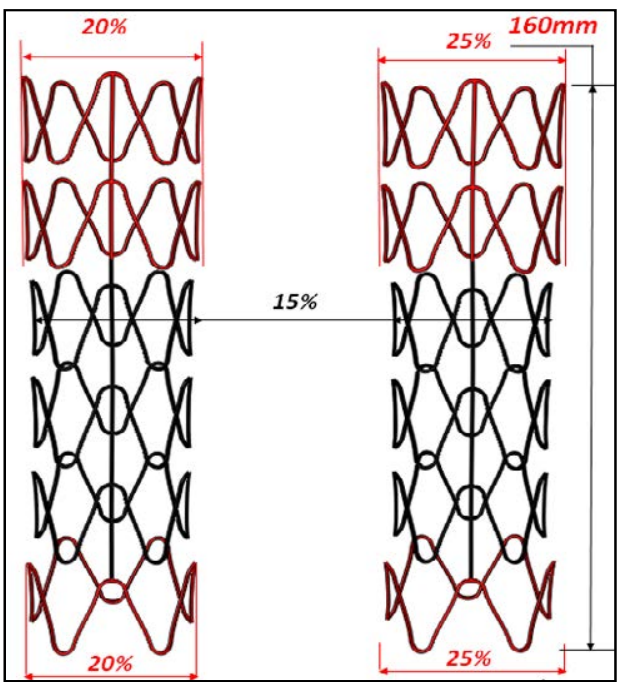

Figure 6: Improved stent 2 designs modeling (Imp-NDSЏ), final optimization. 
Citation: Altnji HE, Said BB, Berre HWL (2015) Numerical Simulation for Design Evaluation of Thoracic Stent Graft to Investigate the Migration Phenomena and Type 1a Endoleak of Thoracic Aneurysm. J Vasc Med Surg 3: 187. doi:10.4172/2329-6925.1000187

Page 6 of 7

\begin{tabular}{|c|c|c|}
\hline $\begin{array}{c}\text { Stent models } \\
\text { (PASL) } \\
\text { (DASL) }\end{array}$ & & $\begin{array}{c}\text { Stent 2(160 mm) } \\
D_{2 P}=21 \\
D_{2 D}=18\end{array}$ \\
\hline \multirow{2}{*}{ Oversizing value (0 \%) } & Stent Body & $15 \%$ \\
\hline & Stent Proximal site (two circles) & $20 \%$ \\
\hline \multirow{2}{*}{ Contact stability $\left(\bar{F}_{\text {CS }}\right)$} & Stent Distal site (one circle) & $20 \%$ \\
$D_{2 D}=18$
\end{tabular}

Table 3: The effect of improved new design stent 2; simulation results.

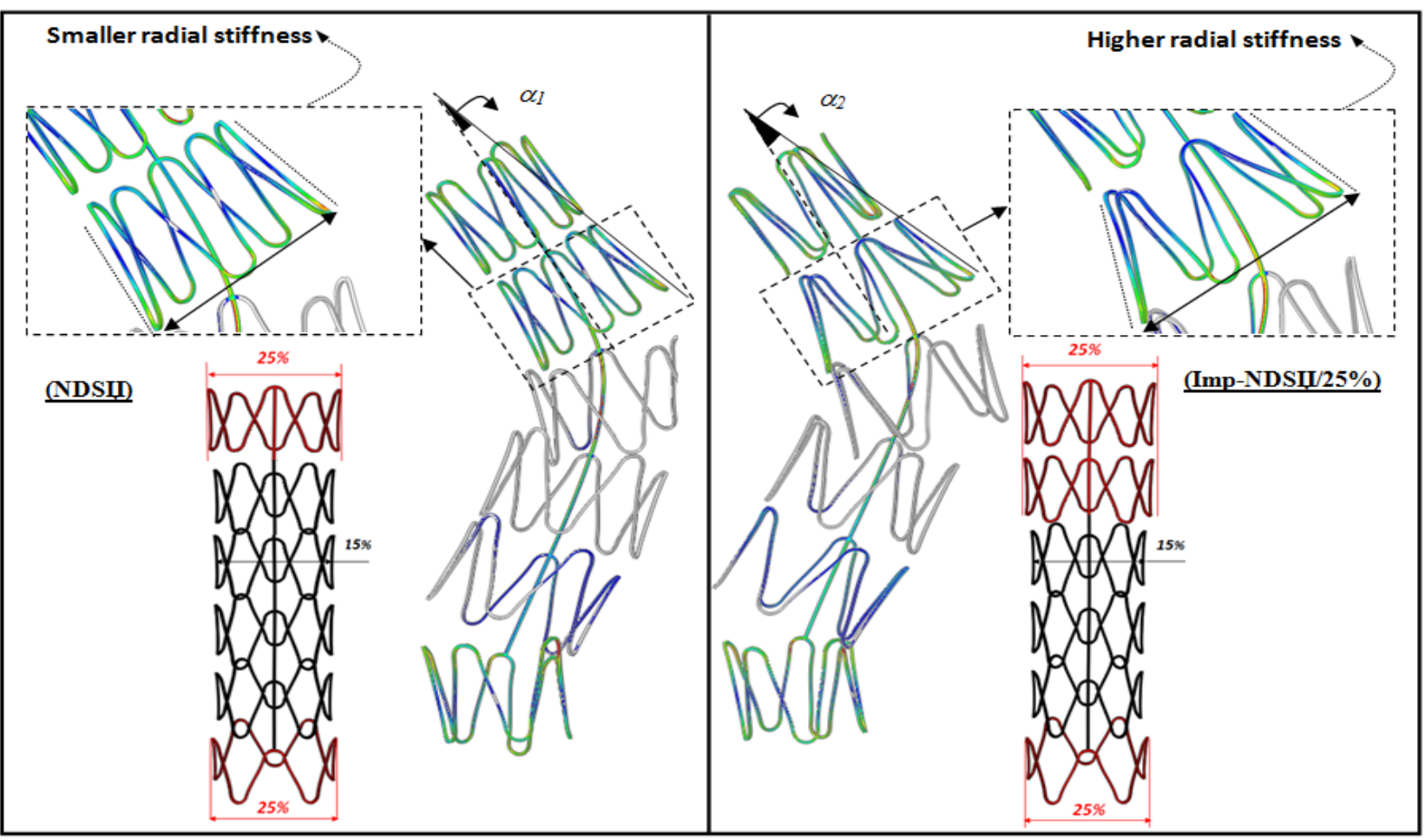

Figure 7: Comparison of superelastic recovery of the struts between the NDSЏ (left) and Imp-NDSЏ of stent 2 (right) after stent deployment.

expansion of the central part of the stent was limited to a $15 \%$ oversizing value. This decreased the potential energy which caused the stent to be dislodged, shortened or migrated by the pullout forces. This observation agrees with other experimental results [19] which associate high oversizing with greater static downward forces, i.e., more risk of stent migration. When the proximal stent length was higher for the new designed stent 2 (NDSЏ), the simulations did not result in better contact stiffness due to the decreased interaction surfaces with the lumen of the aorta. The $(20 \%)$ and $(25 \%)$ oversized proximal end circle will result in a good contact with the aorta, however, the later circle of the struts with (15\%) oversizing resulted in a smaller contact surface and lower contact stiffness comparing with the uniform, old design stent with $(15 \%)$ uniform oversizing.

Therefore, we suggested the extra oversizing (Imp-new design stent 2) for both two circles of the stent. We believe that this new improved design (Imp-NDSЏ) will lead to a more uniform opposition and adequate contact at the proximal attachment zone. The improved design was able to improve the proximal contact stability compared with the (NDSџ). Despite the contact improvement at the proximal site, the improved design caused an increasing of the contact stability $\bar{F}_{c s}$ (decrease in contact stiffness) at the distal site as compared to
(NDSџ-20 and 25\%), i.e., the contact stiffness was decreased distally, (Table 3). This can be explained by decreasing the overall stent recovery distally when adding another oversized circle at the proximal site. As a result, the proximal part of the stent gained significant superelastic recovery compared to the distal part.

Oversizing the distal part of stent also seems to be beneficial. Despite the lower importance of distal end oversizing, this design can increase the overall contact stability and reduce the peak of circumferential stresses at the proximal attachment zone, especially when the stent length is critical.

\section{Limitation}

The main concern in this work is that our having not modeling the graft can contribute to different mechanical behavior [11]. Finally, we hope that future advances will be supported by experimental studies that are required to validate our numerical observations.

\section{Conclusion}

The main objective of this work is to optimize stent design, based on a $3 \mathrm{D}$ finite element platform, to improve the stent flexibility, conformity, migration behavior and contact stiffness. We propose 
Citation: Altnji HE, Said BB, Berre HWL (2015) Numerical Simulation for Design Evaluation of Thoracic Stent Graft to Investigate the Migration Phenomena and Type 1a Endoleak of Thoracic Aneurysm. J Vasc Med Surg 3: 187. doi:10.4172/2329-6925.1000187

extra oversizing at one or both end portions of the stent. The design is able to improve the flexibility, which is a crucial factor in patients with highly tortuous vessels. It also could prevent migration when the stent was in the critical proximal length (stent1) even in the smoothest contact condition and with high angulation. The obtained results clearly show the importance of performing additional oversizing at the ends of the stent, especially in the proximal case [20]. This fact becomes more important when the length of the stent is critical as the case for the stent 1 . It is also necessary to improve the design of stent 2 by oversizing all the struts that are expected to be in contact against the aorta. Here, better contact stiffness, flexibility and superelastic recovery are obtained. Moreover, this design could also prevent the risk of folding or collapse of stent struts by mitigating the energy of eccentric deformation caused by high angulation and oversizing.

\section{Ethical Approval}

Ethical approval was not required. The patient-specific models the same as that employed in a previous study [8]. The patient gave informed consent to the collection and use of data for research purposes.

\section{References}

1. Lumsden A, PHLin, Parodi J (2007) Advanced Endovascular Therapy of Aortic Disease. s.l.:B Futura. Park, H. C. I. S. S. H. D. et al., 2015. A novel ringconnected stent versus conventional GI stents: comparative study of physical properties and migration rates in a canine colon obstruction model. Gastrointest Endosc.

2. Thomas B, Sanchez L (2009) Proximal migration and endoleak: impact of endograft design and deployment techniques. Semin Vasc Surg 22: 201-206.

3. Bosman WM, Steenhoven TJ, Suárez DR, Hinnen JW, Valstar ER, et al. (2010) The proximal fixation strength of modern EVAR grafts in a short aneurysm neck. An in vitro study. Eur J Vasc Endovasc Surg 39: 187-192.

4. Sternbergh WC 3rd, Money SR, Greenberg RK, Chuter TA; Zenith Investigators (2004) Influence of endograft oversizing on device migration, endoleak, aneurysm shrinkage, and aortic neck dilation: results from the Zenith Multicenter Trial. J Vasc Surg 39: 20-26.

5. Albertini JN, Macierewicz JA, Yusuf SW, Wenham PW, Hopkinson BR (2001) Pathophysiology of proximal perigraft endoleak following endovascular repair of abdominal aortic aneurysms: a study using a flow model. Eur J Vasc Endovasc Surg 22: 53-56.

6. Zarins CK, Bloch DA, Crabtree T, Matsumoto AH, White RA, et al. (2003) Stent graft migration after endovascular aneurysm repair: importance of proximal fixation. J Vasc Surg 38: 1264-1272.

7. Fulton JJ, Farber MA, Sanchez LA, Godshall CJ, Marston WA, et al. (2006)
Effect of challenging neck anatomy on mid-term migration rates in AneuRx endografts. J Vasc Surg 44: 932-937.

8. Altnji HE, Bou-Saïd B, Walter-Le Berre H (2015) Morphological and stent design risk factors to prevent migration phenomena for a thoracic aneurysm: A numerical analysis. Med Eng Phys 37: 23-33.

9. Canaud L, Alric P, Desgranges P, Marzelle J, Marty-Ané C, et al. (2010) Factors favoring stent-graft collapse after thoracic endovascular aortic repair. $J$ Thorac Cardiovasc Surg 139: 1153-1157.

10. Conti M, Van Loo D, Auricchio F, De Beule M, De Santis G et al. (2011) Impact of carotid stent cell design on vessel scaffolding: a case study comparing experimental investigation and numerical simulations. J Endovasc Ther 18: $397-406$.

11. De Bock S, lannaccone F, De Santis G, De Beule M, Mortier P, et al. (2012) Our capricious vessels: The influence of stent design and vessel geometry on the mechanics of intracranial aneurysm stent deployment. J Biomech 45: 1353 1359 .

12. Kumar G, Fangsen Cuia, Asawinee Danpinida, Boyang Sub, Jimmy Kim Fatt Hon, et al. (2013) Design and finite element-based fatigue prediction of a new self-expandable percutaneous mitral valve stent. Computer-Aided Design 45: 1153-1158.

13. Singh C, Wang $X$ (2014) A biomimetic approach for designing stent-graft structures: Caterpillar cuticle as design model. J Mech Behav Biomed Mater 30: $16-29$.

14. Park HS, Choo IW, Seo S, Hyun D, Lim S, et al. (2015) A novel, ring-connected stent versus conventional GI stents: comparative study of physical properties and migration rates in a canine colon obstruction model. Gastrointest Endosc.

15. Bae I, Kyung-Seob Lim, Jun-Kyu Park, Dae-Sung Park, So-Youn Lee, et al (2015) Mechanical behavior and in vivo properties of newly designed bare metal stent for enhanced flexibility. Journal of Industrial and Engineering Chemistry 21: 1295-1300.

16. Altnji HE, Bou-Said B, Walter-Le Berre H (2013) Numerical simulation of the migration phenomena and type $1 \mathrm{a}$ endoleak of thoracic aneurysm endograft Comput Methods Biomech Biomed Engin 16 Suppl 1: 36-38.

17. Jedwab MR, Clerc CO (1993) A study of the geometrical and mechanical properties of a self-expanding metallic stent--theory and experiment. J Appl Biomater 4: 77-85

18. Beule (2009) Finite Element Stent Design, Ghent: Ghent University Library Faculty of Engineering

19. Kratzberg JA, Golzarian J, Raghavan ML (2009) Role of graft oversizing in the fixation strength of barbed endovascular grafts. J Vasc Surg 49: 1543-1553.

20. Canaud L, Alric P, Laurent M, Baum TP, Branchereau P, et al. (2008) Proxima fixation of thoracic stent-grafts as a function of oversizing and increasing aortic arch angulation in human cadaveric aortas. J Endovasc Ther 15: 326-334. 